\title{
Experimental Determination of the N 1s/C 1s Relative Sensitivity Factor for XPS
}

\author{
Hidetaka KonNo and Michio InAGaKI \\ Division of Materials Science and Engineering, Graduate School of Engineering, Hokkaido University, \\ Sapporo 060-8628, Japan
}

Keywords XPS, relative sensitivity factor, polyimide, carbonization

The relative sensitivity factor is practically useful for semi-quantitative analysis by X-ray photoelectron spectroscopy (XPS). The accurate values relative to $\mathrm{C} 1 \mathrm{~s}$ peak, however, are not simply determined, since the carbonaceous contamination level on the standard samples is not always estimated correctly.

We are dealing with the carbonization and graphitization of organic polymer films such as polyimide films which are known to be good precursors of highly oriented graphite films. It is known that upon the carbonization of nitrogen-containing polymers such as polyimides, the nitrogen atoms remain in the carbonized films $\mathrm{s}^{1-3}$ and affect the graphitization subsequently carried out. ${ }^{4}$ Therefore, information on the chemical state and amount of nitrogen remaining in the carbonized films is essentially important. We have been studying the carbonization of different types of nitrogen-containing polymer films up to $1200^{\circ} \mathrm{C}$ by XPS, and have reported on the transitions of the states of nitrogen with the carbonization time and temperature. ${ }^{3,5}$ So far, it has not been possible to estimate the surface composition of nitrogen accurately, because with some samples the relative intensity of $\mathrm{N} 1 \mathrm{~s}$ peak to $\mathrm{C}$ 1s peak was proportional to the matrix composition determined by elemental analysis, but not with others. By accumulating a number of XPS data on various polymer films with different thicknesses, however, the difficulty was found to be due to the uniformity of carbonization, which depends on the thickness of the precursor films. In the present work, the relative sensitivity factor of $\mathrm{N} \mathrm{1s} / \mathrm{C} 1 \mathrm{~s}$ was determined by a statistical treatment of the experimental data.

\section{Experimental}

Three types of polyimide films (Kapton, NOVAX and Upilex) and poly-p-phenylene-1,3,4-oxadiazole (POD) film on hand were used: the structure and thickness of the films are shown in Fig. 1. The N/C mole ratios in the film are all different. Carbonization was carried out at temperatures between 500 and $1200^{\circ} \mathrm{C}$ for $1 \mathrm{~h}$ in a flow of high-purity argon. The heating rate was $400 \mathrm{~K}$ $\mathrm{h}^{-1}$. After carbonization, the specimens were kept in a silica gel desiccator of non-grease type.

The XPS measurements were carried out at the normal position by irradiating $\mathrm{Mg} \mathrm{K}_{\alpha} \mathrm{X}$-rays $(15 \mathrm{kV}, 20$ $\mathrm{mA}$ ) with a VG Scientific ESCALAB MkII. The analyzer energy was fixed at $20 \mathrm{eV}$. The X-ray satellites were subtracted by the VG Eclipse data system. The binding energy, $E_{\mathrm{B}}$, was corrected by referring to the $E_{\mathrm{B}}$ of $\mathrm{Au} 4 \mathrm{f}_{7 / 2}$ electrons $(84.0 \mathrm{eV})$ for gold particles sputtered on sample films. The integral intensities were calculated by subtracting background by the Shirley method: ${ }^{6}$ although this procedure is only an approxima$\operatorname{tion}^{7}$, it is useful and valid for uncomplicated spectra having similar background levels at both sides of the peak. ${ }^{7,8}$ The energy ranges for background subtraction were selected to include shake-up satellites and plasmon peak.

The elemental analysis of carbonized film was carried out by a conventional combustion method: about $3 \mathrm{mg}$ of sample was heated up to $900^{\circ} \mathrm{C}$ in a flow of oxygen-
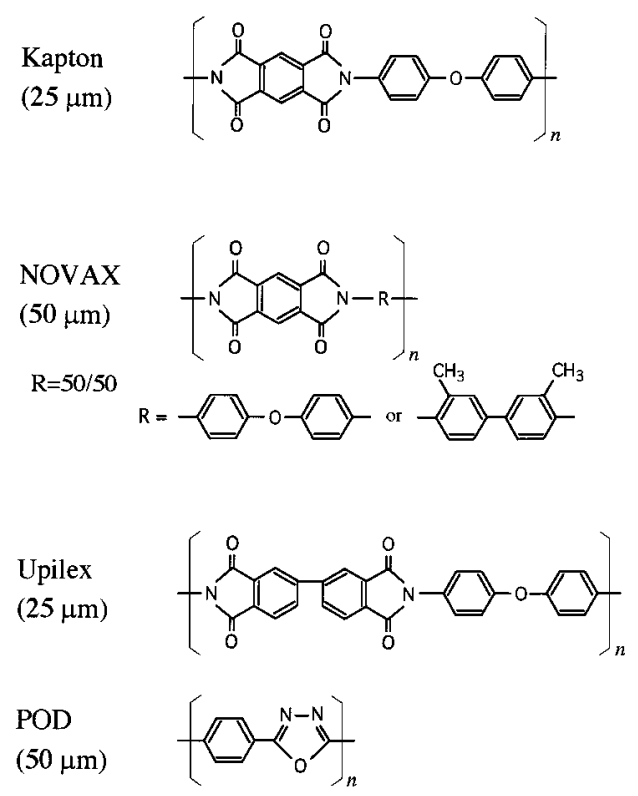

Fig. 1 Structure and thickness of the polymer films used. 
(A)

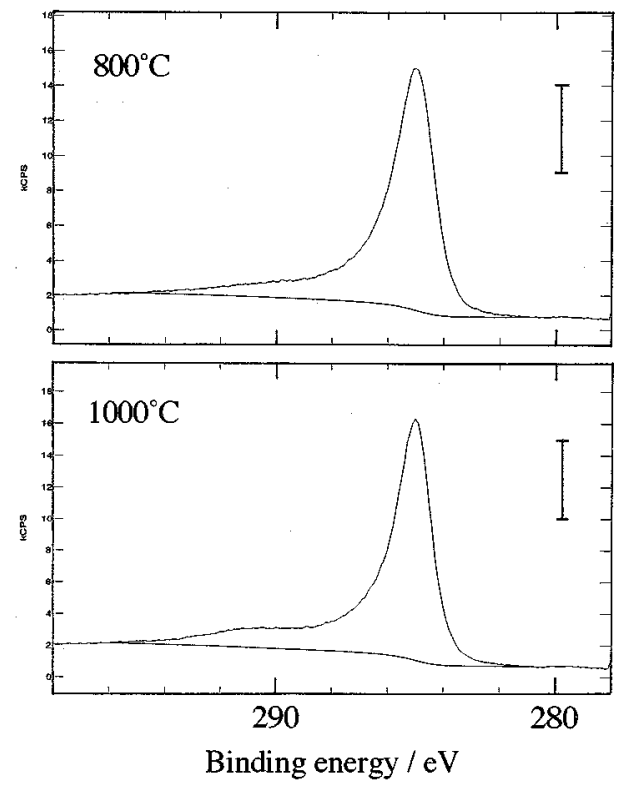

(B)

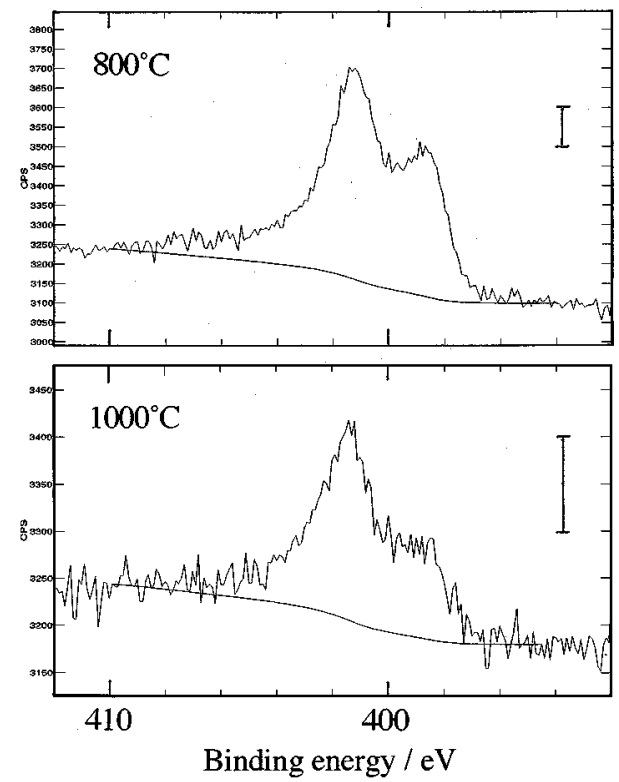

Fig. 2 XPS spectra for carbonized Upilex films: (A) C 1s region, bar indicates $5000 \mathrm{cps}$, and (B) N $1 \mathrm{~s}$ region, bar indicates $100 \mathrm{cps}$.

containing helium gas to analyze for $\mathrm{H}, \mathrm{C}$ and $\mathrm{N}$ $\operatorname{mass} \%$.

\section{Results and Discussion}

Examples of the spectrum and background profile are shown in Fig. 2. The start and the end of background lines were selected at the nearest end of the flat background region, typically, $280-295 \mathrm{eV}$ for $\mathrm{C} 1$ s peak and $394-410 \mathrm{eV}$ for $\mathrm{N} 1 \mathrm{~s}$ peak. The $E_{\mathrm{B}}$ ranges were not exactly the same for each spectrum due to different $S / N$ ratios of the spectrum, as shown in Fig. 2(B), but were taken as similarly as possible. This procedure is important, since the shake-up satellites and plasmon peak of the $\mathrm{C} 1 \mathrm{~s}$ peak become pronounced for specimens carbonized around $1000^{\circ} \mathrm{C}$, as shown in Fig. 2(A). Figure 2(B) also suggests that the background should be determined manually, and not by automatic processing by computer software when the $S / N$ ratio of spectrum is not very high. At least two components are distinguishable from the $\mathrm{N} 1$ s spectra without peak separation: this becomes pronounced above $600^{\circ} \mathrm{C}$, and a higher $E_{\mathrm{B}}$ component survives with increasing temperature and/or time. A lower $E_{\mathrm{B}}$ component around $399 \mathrm{eV}$ is assigned to pyridine type nitrogen and the higher one to nitrogen atoms doped substitutionally in hexagonal carbon layers. Details were reported elsewhere. ${ }^{3,5}$

The peak intensity ratio, $I[\mathrm{~N} 1 \mathrm{~s}] / I[\mathrm{C} 1 \mathrm{~s}]$, was plotted against the matrix composition by elemental analysis. Figure 3 is for carbonized Kapton and Upilex films, and Fig. 4 is for carbonized POD films: the carbonization temperature is not indicated in Fig. 3 for simplicity, but for each sample the upper right point is $500^{\circ} \mathrm{C}$ and the lower left point is $1200^{\circ} \mathrm{C}$. From these results, it is clear that the surface composition of carbonized Kapton and Upilex film is comparable to that of the matrix independent of the temperature, but not for POD. The results for NOVAX, which has a similar molecular structure to that of Kapton and Upilex films but is $50 \mu \mathrm{m}$ in thickness (Fig. 1), also showed a nonlinear relationship similar to that of POD of $50 \mu \mathrm{m}$. If the data between 800 and $1200^{\circ} \mathrm{C}$ in Fig. 4 were taken, they would show some linearity, though we should not be misled by this fact. Evidently, the $50 \mu \mathrm{m}$ films used here were not carbonized uniformly under the present condition. It is reported that polyimide films having a thickness $\geq 50 \mu \mathrm{m}$ do not show a uniform graphite structure even after graphitization at $2950^{\circ} \mathrm{C}$, whereas $25 \mu \mathrm{m}$ films showed a well developed graphite structure. ${ }^{9}$ The present results suggest that ununiformity occurs at the stage of carbonization when the film thickness exceeds a certain limit.

On the 15 data for Kapton and Upilex films in Fig. 3, the linear least squares fitting was carried out and the following relation was obtained:

$$
y=-0.00202+1.75 x \quad r=0.976,
$$

where $y$ is $I[\mathrm{~N} 1 \mathrm{~s}] / I[\mathrm{C} 1 \mathrm{~s}], x$ is $\mathrm{N} / \mathrm{C}$ mole ratio, and $r$ is an interrelation coefficient. The dotted line in Fig. 3 was drawn according to the above relationship. The value of $y$-intercept is not zero, but is negligibly small 


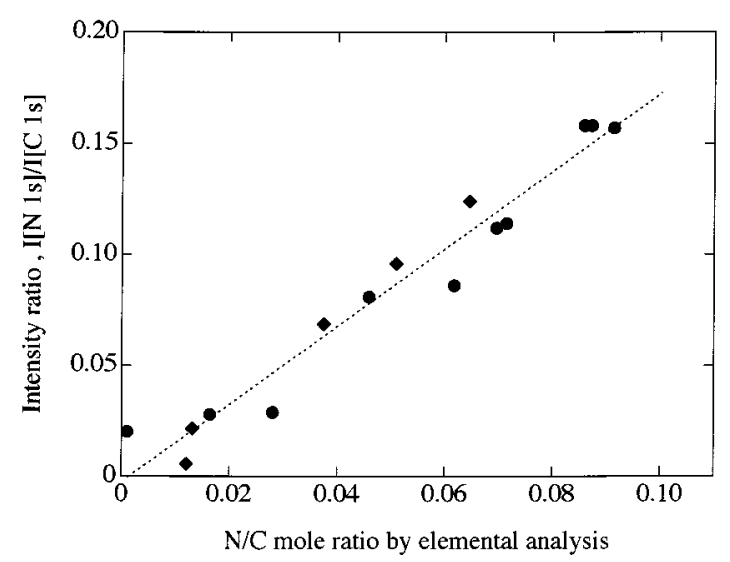

Fig. 3 Relation between the relative intensity by XPS and the matrix composition by elemental analysis for carbonized Kapton (•) and Upilex (•) films.

compared with the slope $(\approx 0.1 \%)$. The correlation analysis showed that the above result is highly significant and that the slope is $1.751 \pm 0.079$ at the $1 \%$ significant level (99\% confidence limits). These results suggest that the surface composition of carbonized Kapton and Upilex films is actually the same as that of the matrix. Consequently, the value 1.75 is useful as the relative sensitivity factor, $s[\mathrm{~N} 1 \mathrm{~s}] / s[\mathrm{C} 1 \mathrm{~s}]$.

Finally, although the present data were taken at a constant analyzer pass energy of $20 \mathrm{eV}$, several data taken at $50 \mathrm{eV}$ with the same specimens coincided with the present ones in Figs. 3 and 4. Therefore, the relative sensitivity factor can be used for a semi-quantitative analysis, when an instrument similar to the present one, namely a concentric hemispherical analyzer, is operated by the same mode. An advantage of the present method is that we can discuss the results based on the known experimental error, though the method is not always applicable. When we use a theoretical equation which is the product of the mean free path for photoelectron, the photoemission cross section, the transfer function of the instrument, and so on, it is rather difficult to estimate the degree of confidence, since some values are empirical approximations.

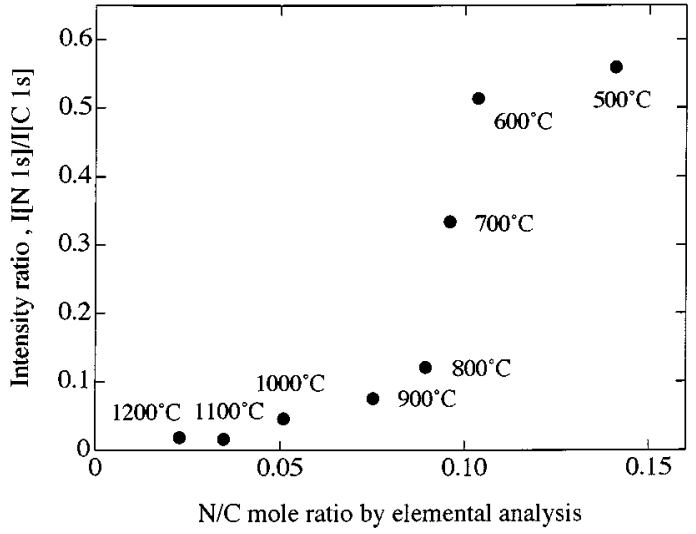

Fig. 4 Relation between the relative intensity by XPS and the matrix composition by elemental analysis for carbonized POD films: carbonization temperature is indicated.

A part of this work was supported by the Research for the Future Program of the Japan Society for the Promotion of Science (JSPS-RFTF96R11701).

\section{References}

1. Y. Hishiyama, A. Yoshida, Y. Kaburagi and M. Inagaki, Carbon, 30, 157 (1992).

2. Y. Hishiyama, K. Igarashi, I. Kanaoka, H. Fujii, T. Kaneda, T. Koidesawa, Y. Shimazawa and A. Yoshida, Carbon, 35, 657 (1997).

3. H. Konno, T. Nakahashi and M. Inagaki, Carbon, 35, 669 (1997).

4. M. Inagaki, H. Tachikawa, T. Nakahashi, H. Konno and Y. Hishiyama, Carbon, 36, 1021 (1998).

5. T. Nakahashi, H. Konno and M. Inagaki, Solid State Ionics, 113-115, 73 (1998).

6. D. A. Shirley, Phys. Rev., B5, 4709 (1972).

7. S. Tougaard, Surf. Interface Anal., 11, 453 (1988).

8. S. Tougaard and C. Jansson, Surf. Interface Anal., 20, 1013 (1993).

9. Y. Hishiyama, A. Yoshida, Y. Kaburagi and M. Inagaki, Carbon, 30, 333 (1992).

(Received January 11, 1999)

(Accepted May 7, 1999) 